\title{
LA ENSEÑANZA DE LA LECTURA CONSIDERADA HISTÓRICAMENTE HASTA 1866
}

\author{
Claudio Matte (1957)
}

El método de lectura más antiguo que se conozca, es el llamado de deletreo o con menos propiedad, según veremos más adelante, silabario. Este método se ha empleado, exclusivamente, desde los tiempos más remotos, hasta una época relativamente reciente y se encuentra todavía en uso en muchos países, a pesar de pugnar con todos los principios pedagógicos reconocidos hoy sin contradicción y de haber sido reemplazado en algunas naciones, por métodos más rápidos, más racionales y más conformes con aquellos principios.

Este hecho podría parecer a primera vista inexplicable; pero estudiando el desarrollo de la instrucción primaria en los diversos países, se llega al convencimiento de que solo es lógico y natural. Esta institución ha seguido en efecto una marcha tan lenta que puede asegurarse que solo en este siglo ha alcanzado la importancia que se le atribuye en la sociedad moderna. Hasta una época reciente, las escuelas primarias estaban entregadas, en la mayor parte de las naciones, a individuos que carecían de toda preparación para su misión y que por lo general solo se dedicaban a esta carrera a falta de ocupaciones más lucrativas. No es, pues, extraño que el preceptorado se ejerciera como un oficio mecánico que solo requiere de práctica y ninguna inteligencia. Como consecuencia lógica de este hecho, no solo la enseñanza de la lectura sino la de todos los otros ramos se hacía de una manera imperfecta.

\section{$[\ldots]$}

Previas estas observaciones, vamos a hacer una reseña del desarrollo histórico de los métodos de lectura, esperando así dar a conocer mejor los empleados actualmente, que no son sino el fruto de las experiencias recogidas durante muchos años.

Según dijimos al principio, el método de lectura más antiguo es el llamado deletreo o silabario. Todos conocen este método, puesto que todos en Chile, como en los demás países de lengua española, hemos aprendido a leer deletreando. Según él, los niños aprenden primero la forma y el nombre de las letras y, una vez que las han aprendido todas, pasan a formar las diferentes combinaciones que son posibles entre ellas. Después de permanecer largo tiempo ocupados en aquel trabajo ingrato y abstracto, tropiezan, al efectuar las combinaciones, con las dificultades que resultan de la diferencia que existe entre el nombre de las consonantes y su valor efectivo en la lengua hablada. Después de enseñar que "b" se llama "be", el maestro tiene que enseñar que "ba" se pronuncia "ba" y no "bea", como el alumno se lo imaginaría, si se atuviera a lo aprendido. De aquí este otro trabajo lento y fatigoso que de nuevo no ofrece interés alguno al niño, que solo 
abruma su memoria y que por desgracia tiene que repetirse para cada una de las numerosas combinaciones a que se presentan las letras del idioma. Por eso vemos también que las cartillas compuestas, según este método, llenan el mayor número de sus páginas con largas listas de sílabas sin significado, que tienen que aprenderse, no como una aplicación de lo aprendido anteriormente, sino casi como otras tantas novedades de la lengua. Este trabajo sería verdaderamente superior a las fuerzas de los niños, si estos, al cabo de un buen número de ejercicios no llegaran a deducir como por instinto el valor efectivo de las consonantes. El trabajo es, con todo, por demás arduo, y aun en los tiempos más antiguos, los maestros, a pesar de su ignorancia, se quejaban de los defectos de este método, sin atinar, sin embargo, a corregirlos de manera eficaz.

$[\ldots]$

En los siglos XVII y XVIII se hicieron diversas tentativas para reformar el método de deletreo y aun en algunas ocasiones se llegó hasta ensayar con buen éxito el método fonético. Pero como la generalidad de los preceptores carecían todavía de la preparación necesaria, estos ensayos no encontraron eco en las escuelas.

Todos estaban, sin embargo, más o menos de acuerdo en reconocer los defectos del método de deletreo; los escritos publicados en su contra eran muy numerosos; en ellos se le abrumaba de reproches, se le acusaba de aburrido, de lento, de exigir un trabajo enorme de la memoria sin tomar para nada en cuenta la inteligencia.

\section{$[\ldots]$}

Entre los numerosos medios propuestos para facilitar y hacer más interesante la enseñanza, merece ser mencionado a causa de su curiosidad el que consistía en dar a los niños galletas que tenían exactamente las formas de las diversas letras del alfabeto, a fin de que así las retuvieran mejor. Uno de los partidarios de este procedimiento, Basedord, después de reconocer la aridez del método de deletreo y la repulsión que inspiraba a los niños, decía en una obra publicada en 1784, que para remediar estos inconvenientes era necesario hacer la enseñanza "dulce como el azúcar", y al proponer el recurso de las galletas, agregaba como para desarmar toda resistencia: "¿Qué pueden costar estas galletas? Muy poco. Los niños tienen por necesidad que desayunarse y en lugar de pan se les puede dar de desayuno letras de masa un poco mejor que la ordinaria. Por experiencia podemos decir que ningún niño necesita comer letras más de cuatro semanas". Excusado parece agregar que recursos de esta naturaleza no podían surtir efecto alguno.

Después de tantos esfuerzos inútiles, el método sufrió en Alemania, hacia fines del siglo XVIII, una modificación importante que lo acercaba un tanto al fonético. Consistía esta en enseñar primero las vocales y después las diversas combinaciones de estas con las consonantes, sin nombrar estas últimas. Los alumnos solo necesitaban saber qué efecto produce la consonante puesta al lado de la vocal y aprendían después por deducción, y sin darse cuenta exacta, el valor fonético de aquella. Así, una vez que conocían las vocales, los alumnos aprendían como un todo las sílabas "ba", "be", "bi", "bo", "bu", 
después las sílabas "ab", "eb", etc., en seguida "bad", "dab", etc., y así sucesivamente. Este método merece, pues, con más propiedad el nombre de silabario, puesto que toma las sílabas como base para la enseñanza de la lectura, mientras que al otro corresponde más bien la designación de método de deletreo, por tomar como base las letras en el significado más usual de esta palabra, es decir, en el de nombre de los elementos simples del idioma.

\section{$[\ldots]$}

Hasta aquí hemos visto que la lectura se enseñaba separadamente de la escritura. La enseñanza simultánea de ambas había sido, sin embargo, propuesta y practicada a manera de ensayo en diversos países: así, por ejemplo, en Alemania a principios del siglo XVII por Comenius y Ratichius; en Inglaterra a fines del siglo pasado y principios del presente por Bell y Lancaster; en Francia se había seguido este procedimiento desde tiempos muy antiguos, pues Montaigne, que vivió de 1533 a 1592, asegura que a él le enseñaron a leer y escribir simultáneamente, haciéndole poner las letras bajo papel transparente, de suerte que no tenía más que trazar sus formas, rasgo por rasgo [...]. Las ventajas de este procedimiento son indiscutibles: en primer lugar, mediante él, los niños graban mucho mejor en su memoria las formas de las letras, pues, para copiarlas necesitan observarlas con exactitud en todos sus detalles; con auxilio de él se introduce también variedad en la enseñanza, circunstancia que es muy digna de tomarse en cuenta, especialmente cuando se trata de niños de corta edad que no pueden ni deben ocupar mucho tiempo su mente en una misma cosa y se les proporciona además el placer de satisfacer su instinto natural de actividad; para las clases, por último, que cuentan un gran número de alumnos y un solo preceptor, este procedimiento ofrece la ventaja de que mientras el maestro atiende a una parte de sus alumnos, puede hacer que la otra se ocupe de escribir.

$[\ldots]$

El método resultante de estas dos reformas, fonetismo y escritura, era muy superior al deletreo, y luego ganó terreno entre los preceptores, que ahora estaban mejor preparados para ponerlo en práctica. El método tenía, sin embargo, todavía defectos graves, consistentes, según hemos dicho más arriba, en la falta de interés que ofrecía a los alumnos el aprendizaje de sonidos y de combinaciones sin significado.

A corregir este defecto contribuyó poderosamente el método ideado por un francés, Jacocot [...] Su principio capital consistía en hacer partir toda enseñanza de hechos concretos y no de abstracciones; según él, la gramática no debía jamás enseñarse por medio de definiciones y reglas, sino que los alumnos mismos debían deducir estas de la lengua. De la misma manera, la enseñanza de la lectura debía comenzar por frases y palabras que algo representan y no por sonidos y sílabas que nada significan.

$[\ldots]$ 
Jacocot describe en seguido el procedimiento empleado por él. Según su método, cualquier libro cuyo contenido sea comprensible para niños, puede servir de texto; como admirador de Fenelón, se servía él de Telémaco y procedía de la manera siguiente. Leía en voz alta y clara la primera frase del libro: Calypso ne pouvait se consoler du depart d'Ulyse, mostrando con el dedo cada una de las palabras y haciendo que los alumnos las repitieran con pronunciación correcta hasta que las aprendieran todas de memoria. Una vez conseguido esto, pronunciaba las palabras por su orden y fuera de él, haciendo esta vez que los alumnos mismos las señalaran a medida que las nombraban, después mostraba él las palabras y los niños las pronunciaban. Tan pronto como los alumnos no encontraban dificultad alguna en estos ejercicios, descomponía Jacocot cada palabra en sus sílabas, y procedía respecto de estas, lo mismo que antes respecto de aquellas. Una vez que los alumnos reconocían sin dificultad todas las sílabas, las descomponía en sus letras y aplicaba a estas un procedimiento análogo. Por medio de este sistema, esencialmente analítico, puesto que se partía de un todo hasta llegar a las partes más simples, los alumnos aprendían las letras, y siguiendo después un procedimiento muy contrario, las combinaban para formar de nuevo el todo. Jacocot enseñaba también simultáneamente la escritura, pues tan pronto como la frase había sido descompuesta en sus letras, hacía que el alumno aprendiera a escribirla.

\section{$[\ldots]$}

De entonces acá se ha compuesto, según este procedimiento, un gran número de libros de lectura, que varían entre sí en detalles que, si bien son importantes, no afectan al fondo mismo del método. Así es, por ejemplo, el número de palabras empleadas para la enseñanza. Algunos contienen muchas, otros pocas; también es vario el orden en que las diferentes letras aparecen; algunos toman especialmente en consideración para este orden la dificultad de la escritura; otros la de la pronunciación. Algunos autores enseñan al principio solo los caracteres manuscritos, dejando para más tarde los impresos, otros enseñan ambos caracteres a la vez.

\section{$[\ldots]$}

Resumiendo lo expuesto en los párrafos anteriores, tenemos que el método más antiguo y más imperfecto es el de deletreo llamado también silabario. Los defectos de este método consisten: primero, en que dificulta y demora el aprendizaje, dando a las letras un valor que no corresponde al que tienen en las sílabas y las palabras, y segundo, en que exigiendo única y exclusivamente el empleo de la memoria, no desarrolla las demás facultades y hace la enseñanza mecánica, monótona y aburrida. Séanos permitido, antes de pasar adelante, citar aquí las palabras con que un notable pedagogo y filósofo contemporáneo expresa en general un principio que tiene perfecta aplicación al caso presente: "El que en la enseñanza solo persigue el éxito, el que exige de sus alumnos un conocimiento sin considerar el trabajo que su adquisición les impone y la influencia que 
este ejerce sobre su espíritu, está en flagrante pugna con los preceptos de la verdadera pedagogía" [...]

El que, a pesar de todo, este método se haya mantenido por tanto tiempo y se mantenga aún en muchos países, es debido a la poca preparación que los preceptores tenían y aún tienen.

$[\ldots]$

En un informe sobre la instrucción primaria en la Exposición Universal de Filadelfia en 1876, compuesto por una comisión nombrada por el Ministerio de Instrucción Pública de Francia, encontramos a este respecto datos que nos permiten formar un juicio exacto acerca de la enseñanza de la lectura en ese país. "El método de deletreo — dice el informe- no se emplea ya en las buenas escuelas de Estados Unidos; aún entre las escuelas no hay más de 20 sobre 100, por término medio, que se sirvan de él. Hay Estados enteros en que ni siquiera se le conoce. La opinión pública se ha pronunciado evidentemente por los nuevos métodos... La Alemania ha suministrado muchos de sus procedimientos, los cuales han sido ingeniosamente modificados y aplicados". Según este informe, los métodos más usados son: el llamado phonetic method, que es el método fonético puramente sintético y el word method, que equivale al analítico sintético, "que es más atrayente para los niños". "Los ejercicios preparatorios de la lectura están bastante generalizados". Por lo general, según el informe, la lectura no se enseña simultáneamente con la escritura, pero en los últimos años se han hecho algunos ensayos en este sentido y con tan buen resultado que la idea de combinar ambas enseñanzas ha ganado rápidamente terreno. 